This item was submitted to Loughborough's Research Repository by the author.

Items in Figshare are protected by copyright, with all rights reserved, unless otherwise indicated.

\title{
An integrated framework on characterization, control, and testing of an electrical turbocharger assist
}

PLEASE CITE THE PUBLISHED VERSION

https://doi.org/10.1109/TIE.2017.2774726

\section{PUBLISHER}

Institute of Electrical and Electronics Engineers

\section{VERSION}

VoR (Version of Record)

\section{PUBLISHER STATEMENT}

This work is made available according to the conditions of the Creative Commons Attribution 3.0 International (CC BY 3.0) licence. Full details of this licence are available at: https://creativecommons.org/licenses/by/3.0/

\section{LICENCE}

CC BY 3.0

\section{REPOSITORY RECORD}

Zhao, Dezong, Edward Winward, Zhijia Yang, Richard Stobart, Byron Mason, and Thomas Steffen. 2017. "An Integrated Framework on Characterization, Control, and Testing of an Electrical Turbocharger Assist". Loughborough University. https://hdl.handle.net/2134/27311. 


\title{
An Integrated Framework on Characterization, Control, and Testing of an Electrical Turbocharger Assist
}

\author{
Dezong Zhao ${ }^{(\mathbb{1}}$, Senior Member, IEEE, Edward Winward ${ }^{(0)}$, Zhijia Yang ${ }^{\left({ }^{\circledR}\right.}$, \\ Richard Stobart ${ }^{(\mathbb{D}}$, Member, IEEE, Byron Mason ${ }^{(\mathbb{D}}$, and Thomas Steffen ${ }^{(\mathbb{1}}$, Member, IEEE
}

\begin{abstract}
Electrical turbocharger assist is one of the most critical technologies in improving fuel efficiency of conventional powertrain vehicles. However, strong challenges lie in high efficient operations of the device due to its complexity. In this paper, an integrated framework on characterization, control, and testing of the electrical turbocharger assist is proposed. Starting from a physical characterization of the engine, the controllability and the impact of the electrical turbocharger assist on fuel economy and exhaust emissions are both analyzed. A multivariable robust controller is designed to regulate the dynamics of the electrified turbocharged engine in a systematic approach. To minimize the fuel consumption in real time, a supervisory level controller is designed to update the setpoints of key controlled variables in an optimal way. Furthermore, a cutting-edge experimental platform based on a heavy-duty diesel engine is built. The proposed framework has been evaluated in simulations, physical simulations, and experiments. Results are presented for the developed system and the proposed framework that demonstrate excellent tracking performance, high robustness, and the potential for improvements in fuel efficiency.
\end{abstract}

Index Terms-Electrical turbocharger assist (ETA), multivariable control, real-time energy management, system characterization, testing framework design.

\section{NOMENCLATURE}

GHG Greenhouse gas.

EM Electrical machine.

ETA Electrical turbocharger assist.

TDE Turbocharged diesel engine.

ETDE Electrified turbocharged diesel engine.

Manuscript received April 2, 2017; revised July 14, 2017 and September 30, 2017; accepted October 26, 2017. Date of publication December 4, 2017; date of current version February 13, 2018. This work was supported in part by the Innovate U.K. (formerly the Technology Strategy Board UK), under a grant for the Low Carbon Vehicle IDP4 Programme under Grant TP14/LCV/6/I/BG011L and in part by the Engineering and Physical Sciences Research Council of U.K. under Grant EP/R512941/1. (Corresponding author: Dezong Zhao.)

The authors are with the Department of Aeronautical and Automotive Engineering, Loughborough University, Loughborough LE11 3TU, U.K. (e-mail: d.zhao@lboro.ac.uk; e.winward@lboro.ac.uk; z.yang2@lboro. ac.uk; r.k.stobart@lboro.ac.uk; b.mason2@lboro.ac.uk; t.steffen@lboro. ac.uk).

Color versions of one or more of the figures in this paper are available online at http://ieeexplore.ieee.org.

Digital Object Identifier 10.1109/TIE.2017.2774726

\author{
VGT Variable geometry turbocharger. \\ EGR Exhaust gas recirculation. \\ SRM Switched reluctance motor. \\ AFR Air-fuel-ratio. \\ BSFC Brake specific fuel consumption. \\ $\mathrm{NO}_{x} \quad$ Nitrogen oxides. \\ PM Particulate matter. \\ SISO Single-input single-output.
}

NRMSD Normalized root-mean-square deviation.

ECU Engine control unit.

PMSM Permanent magnet synchronous motor.

SOC State of charge.

$N \quad$ Engine speed, $\mathrm{r} / \mathrm{min}$.

$T_{L} \quad$ Engine load, $\mathrm{N} \cdot \mathrm{m}$.

$W_{f} \quad$ Engine fuelling rate, $\mathrm{kg} / \mathrm{s}$.

$W_{e} \quad$ Total mass flow rate to cylinders, $\mathrm{kg} / \mathrm{s}$.

$W_{c} \quad$ Compressor air mass flow rate, $\mathrm{kg} / \mathrm{s}$.

$W_{\text {egr }} \quad$ EGR mass flow rate, $\mathrm{kg} / \mathrm{s}$.

$W_{t} \quad$ Gas mass flow rate through the turbine, $\mathrm{kg} / \mathrm{s}$.

$P_{c} \quad$ Compressor power, $\mathrm{kW}$.

$P_{t} \quad$ Turbine power, kW.

$P_{\text {em }} \quad$ ETA power, $\mathrm{kW}$.

$P_{b} \quad$ Engine brake power, $\mathrm{kW}$.

$T_{\text {in }} \quad$ Intake manifold temperature, $\mathrm{K}$.

$T_{\text {exh }} \quad$ Exhaust manifold temperature, $\mathrm{K}$.

$T_{\text {egr }} \quad$ Mass flow temperature at the EGR outlet, K.

$T_{c} \quad$ Air temperature at the compressor outlet, $\mathrm{K}$.

$T_{\text {gas }} \quad$ Exhaust gas temperature from the engine, $\mathrm{K}$.

$T_{a} \quad$ Ambient temperature, $\mathrm{K}$.

$p_{\text {in }} \quad$ Intake manifold pressure, $\mathrm{kPa}$.

$p_{\text {exh }} \quad$ Exhaust manifold pressure, $\mathrm{kPa}$.

$V_{\text {in }} \quad$ Intake manifold volume, $\mathrm{m}^{3}$.

$V_{\text {exh }} \quad$ Exhaust manifold volume, $\mathrm{m}^{3}$.

$\omega \quad$ Turbine speed, $\mathrm{r} / \mathrm{min}$.

$J \quad$ Turbine shaft moment of inertia, $\mathrm{kg} / \mathrm{s}^{2}$.

$\eta_{c} \quad$ Compressor isentropic efficiency.

$\eta_{t} \quad$ Turbine isentropic efficiency.

$\eta_{v} \quad$ Volumetric efficiency.

$\eta_{m} \quad$ Turbocharger mechanical efficiency.

$\chi_{\text {egr }} \quad$ EGR valve opening.

$\chi_{\text {vgt }} \quad$ VGT vane opening.

$R_{g} \quad$ Specific gas constant, $0.292 \mathrm{~kJ} /(\mathrm{kgK})$.

$\gamma \quad$ Specific heat ratio, 1.4 . 


\section{INTRODUCTION}

I $\mathrm{N}$ THE coming decades, efforts are required to achieve the GHG emissions reduction target made in the Paris Climate Change Conference 2015. Transportation sector accounts for approximately one quarter of GHG emissions and half of global oil consumption [1]. Meanwhile, with the higher demand on energy, the fossil oil reserve is depleting at a faster pace than in the past. The fuel consumption reduction in the transportation sector is now a globally critical issue [2]. Engine downsizing is proven as one of the most promising approaches to fuel consumption reduction in vehicles [3]. It is expected a smaller capacity engine can provide the power previously delivered by a larger engine. In downsized engines, the average engine operating points are closer to its high fuel efficiency zone at high loads. Furthermore, the fuel economy benefits are also achieved through reduced friction, reduced heat transfer across the cylinder walls, and reduced pumping losses. The loss of reduced engine displacement is compensated by more effective air charging, where the predominant technology is the VGT. In VGT-equipped engines, part of the exhaust gas energy is used to accelerate the turbine shaft for boosting, therefore both engine transient response and fuel economy are improved. However, the turbo-lag in the VGT is still nonnegligible, since the demand torque cannot be satisfied immediately due to limited fresh air mass flow. To overcome the transient performance limitations, a more responsive system is required to work cooperatively with the VGT, which is the motivation for developing the ETA [4].

Compared with other electrically assisted boosting systems, the ETA can achieve higher fuel efficiency than the electric supercharger [5]-[7] and electric turbocompounding [8]-[10]. The electric supercharger and the turbocharger work as a twostage system, with the EM and compressor connected in series. The electric supercharger increases the intake air mass flow, and therefore improves the transient response, especially at low engine speeds. However, the fuel efficiency is limited because the electric supercharger is powered from an external power source or engine crankshaft [11]. In the electric turbocompounding, a power turbine is installed downstream of the main turbine. When the main turbine provides more boosting power than required, the extra power is recuperated by the power turbine to assist an EM mounted on the crankshaft. However, there are mechanical losses in multiple energy transfers and therefore the fuel efficiency is reduced [12]. In the ETA, the EM is powered by previously recovered exhaust gas energy stored in a battery, so lower pumping and mechanical losses are suffered. The development of ETA has attracted wide interest from engine and turbocharger manufacturers. Detroit Diesel has conceptualized a prototype electrically assisted turbocharger to improve transient response and enhance exhaust energy recovery capability [13]. Honeywell presented their early design and development of electrical assist technology on diesel engines, referred to as e-Turbo [14]. MHI reported their development of a hybrid turbo that achieves better combustion and reduced emissions [15]. However, the diesel exhaust system is a harsh environment (e.g., high $T_{\text {exh }}$ of approximately $700{ }^{\circ} \mathrm{C}$ ) for an EM and as such designs are still at an early stage.
There are several challenges in developing the ETA. Primarily, a reliable ultrahigh speed EM with small inertia is required to be mounted on the turbine shaft. Also, the high efficient thermal regulation is essential to prevent overheating. Recent technical progresses have been made to overcome the obstacles. Advances in power electronics have led to the development of EM, which can run higher than $100 \mathrm{kr} / \mathrm{min}$ [16]. By choosing an EM with simple structure, such as a SRM or a PMSM, the thermal regulation challenges are reduced. An entirely new ETA has been recently developed by a consortium led by Caterpillar Inc. The ETA is used to downsize a 9.3 L engine to 7.1 L [17].

To generalize the application of ETA, the key to the success is high-efficient online energy management and control. In detail, the EM should work with other air system actuators in a systematic and coordinated manner. To underpin this work, a thorough characterization of the ETDE is essential. Following the characterization, a control strategy is desired to regulate the energy flows in intake/exhaust manifolds and exhaust/EGR pipes. To facilitate demonstration and further development, design of an open testing platform which is compatible with existing engine testing chassis is necessary. This paper proposes an integrated framework on characterization, control, and testing of ETA. The main contributions of this work are the following.

1) Physical characterization of the ETDE, in particular the controllability analysis and the impact of ETA on fuel economy and exhaust emissions.

2) A multivariable robust controller dealing with air system internal couplings and external disturbances.

3) A real-time energy management module to optimize the energy flow distribution.

4) An integrated testing framework that is open to various engine control and testing schemes.

This paper is organized as follows. After the introduction in Section I, the ETDE is modeled and characterized in Section II. The multivariable controller and the energy management module are designed in Sections III and IV, respectively. The experiments are elaborated in Section V. Finally, the conclusions are summarized in Section VI.

\section{SYSTEM DESCRIPTION, MODELING, AND CHARACTERIZATION}

\section{A. System Description}

The layout of the ETDE is illustrated in Fig. 1. The ETA is a single stage turbocharger without waste gate. All of the engine exhaust gas (after the EGR) passes through the ETA turbine at all times. The expansion of the exhaust gas across the turbine produces mechanical power, which is transferred to the compressor via a common shaft. The compressor converts this mechanical power into increased pressure of the fresh air into the engine. The EM can work in either motoring or generating mode. In motoring mode, the EM extracts energy from the battery to assist boosting. In generating mode, energy is extracted from the exhaust gas to charge the battery. When the EM is generating, some of the mechanical shaft power delivered by the turbine is converted into electrical power. Therefore, the turbine speed 


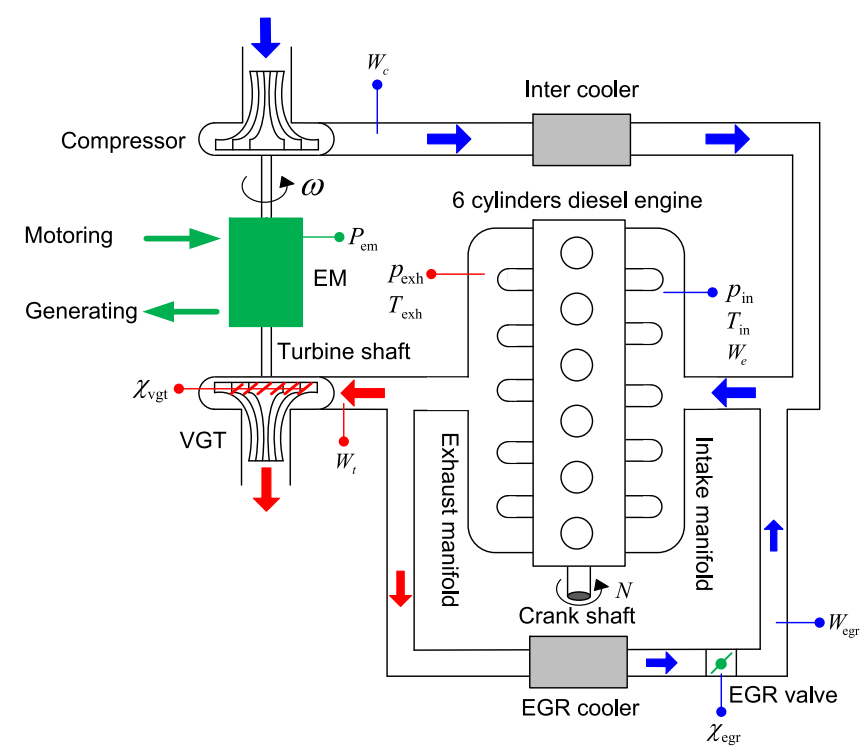

Fig. 1. Electrified turbocharged diesel engine.

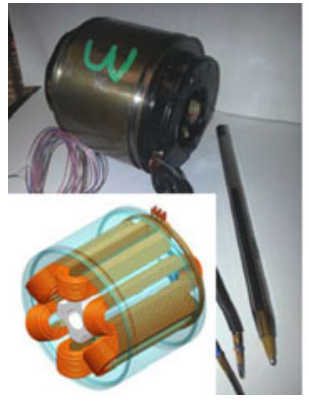

(a)

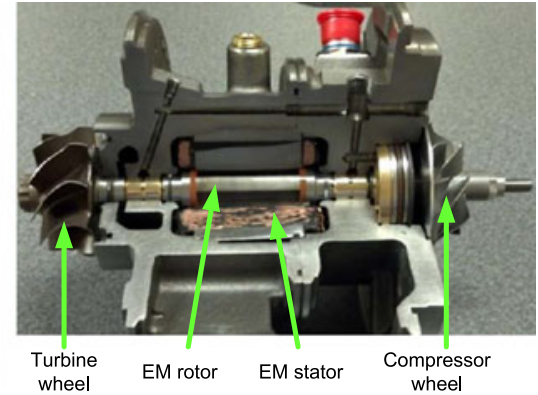

(b)
Fig. 2. SRM and ETA. (a) SRM. (b) ETA.

will decrease unless the VGT vanes are closed to increase the delivered mechanical power. In the proposed work, a SRM is selected as the EM because of its simple structure. The SRM is shown in Fig. 2(a), and the ETA with an integrated SRM is shown in Fig. 2(b).

To demonstrate the effectiveness of the ETA in improving transient performance, simulations have been completed on a CAT C7.1 heavy-duty ETDE model, where the rated power of the EM is $5 \mathrm{~kW}$. The engine runs at a speed of $1800 \mathrm{r} / \mathrm{min}$, while the load rises from $100 \mathrm{~N} \cdot \mathrm{m}$ at $20 \mathrm{~s}$ to $800 \mathrm{~N} \cdot \mathrm{m}$ at $21 \mathrm{~s}$. By applying different EM power in transients, the six-case results are illustrated in Fig. 3. In Fig. 3(a), the engine speed drops suddenly at $20 \mathrm{~s}$ because of the load acceptance. With the increasing $P_{\mathrm{em}}$, the drop on $N$ gradually diminishes and $N$ recovers faster. This is because the increased $W_{c}$ as shown in Fig. 3(b) and increased $p_{\text {in }}$ in Fig. 3(c). This results in increased available air mass in the cylinder, which allows more fuel to be injected during the load acceptance, without sacrificing AFR.

\section{B. Modeling and Characterization}

Based on the conservation laws of mass and energy, the dynamics of the ETDE air system are represented by the pressure changes on $p_{\text {in }}, p_{\text {exh }}, m_{1}$, and $\omega$ as follows:

$$
\begin{gathered}
\dot{p}_{\text {in }}=\frac{R_{g} \gamma}{V_{\text {in }}}\left(W_{c} T_{c}+W_{\text {egr }} T_{\text {egr }}-W_{e} T_{\text {in }}-\frac{\dot{Q}_{1}}{c_{p}}\right) \\
\dot{p}_{\text {exh }}=\frac{R_{g} \gamma}{V_{\text {exh }}}\left(W_{\text {in }} T_{\text {gas }}-W_{\text {exh }} T_{\text {exh }}-\frac{\dot{Q}_{2}}{c_{p}}\right) \\
\dot{\omega}=\frac{1}{J \omega}\left(\eta_{m}\left(P_{t}+P_{\text {em }}\right)-P_{c}\right) \\
\dot{m}_{1}=W_{c}+W_{\text {egr }}-W_{e}
\end{gathered}
$$

where $W_{\text {in }}=W_{e}+W_{f}$, and $W_{\text {exh }}=W_{\text {egr }}+W_{t} ; \dot{Q}_{1}$ and $\dot{Q}_{2}$ indicate the heat losses in the intake and exhaust manifolds, respectively. The bearing power losses on the turbine shaft and windage losses in the ETA are quantified by $\eta_{m}$. Strong nonlinearities exist in the air system for the mass flow exchanges among the EGR, VGT, compressor, and manifolds. The mass flow rates and powers can be expressed implicitly as

$$
\begin{aligned}
W_{\text {egr }} & =f\left(p_{\text {in }}, p_{\text {exh }}, \chi_{\text {egr }}\right) \\
W_{e} & =f\left(p_{\text {in }}, T_{\text {in }}, \eta_{v}, N\right) \\
W_{t} & =f\left(p_{\text {exh }}, T_{\text {exh }}, \chi_{\text {vgt }}\right) \\
W_{c} & =f\left(p_{\text {in }}, \omega\right) \\
P_{t} & =f\left(W_{t}, T_{\text {exh }}, p_{\text {exh }}, \eta_{t}\right) \\
P_{c} & =f\left(W_{c}, p_{\text {in }}, p_{a}, \eta_{c}\right) .
\end{aligned}
$$

$W_{\text {egr }}$ is modeled as the standard orifice equation, whereas $W_{e}$ is modeled by the speed-density equation. $W_{t}$ and $W_{c}$ are modeled as nonlinear functions with respect to the efficiencies $\eta_{t}$ and $\eta_{c}$, which are generated in offline mapping. The relationship between power and mass flow on both compressor and turbine sides are also derived from $\eta_{t}$ and $\eta_{c}$.

Physical characterization of the ETA based on simulation results provides a basis to support the ETDE control. The characterization work is categorized into the following three aspects:

1) the impacts of the ETA on fuel economy;

2) the impacts of the ETA on exhaust emissions;

3) the controllability of the ETDE.

Case studies are made at the operating point of $(1800 \mathrm{r} / \mathrm{min}$, $800 \mathrm{~N} \cdot \mathrm{m})$, whereas the engine behavior at $\chi_{\text {egr }}=0.3$ and $\chi_{\text {egr }}=0$ are both investigated. Simulation results are shown in Fig. 4. In the case of $\chi_{\text {egr }}=0.3, \chi_{\mathrm{vgt}}$ are set as $0.2,0.3$, and 0.4 , respectively. In the case of $\chi_{\mathrm{egr}}=0, \chi_{\mathrm{vgt}}$ are set as $0.4,0.5$, and 0.6 , respectively. In both cases, $P_{\mathrm{em}}$ varies from -5 to $5 \mathrm{~kW}$, with the step of $2.5 \mathrm{~kW}$.

1) Analysis on Fuel Economy: In both Fig. 4(a) and (d), when $\chi_{\mathrm{vg}}$ is fixed, BSFC declines when $P_{\mathrm{em}}$ rises, indicating the fuel efficiency is improved with higher EM motoring power. There are two reasons for this. First, higher $P_{\mathrm{em}}$ would lead to an increased AFR with no requirement for more $P_{t}$ and therefore, the pumping losses are reduced. Second, the increased AFR makes the combustion more efficient and consequently, the thermal efficiency improves as well. When $P_{\mathrm{em}}$ is fixed, BSFC increases when $\chi_{\mathrm{vgt}}$ is more closed. This is because the turbine shaft spins faster and then pumping losses and mechanical losses 


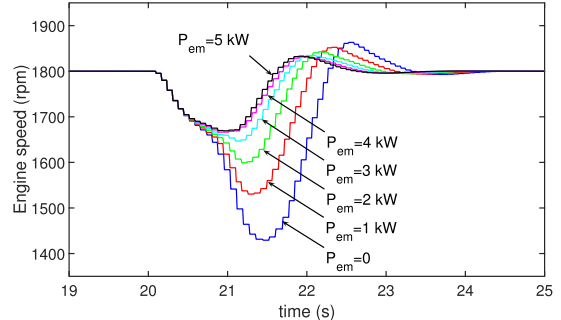

(a)

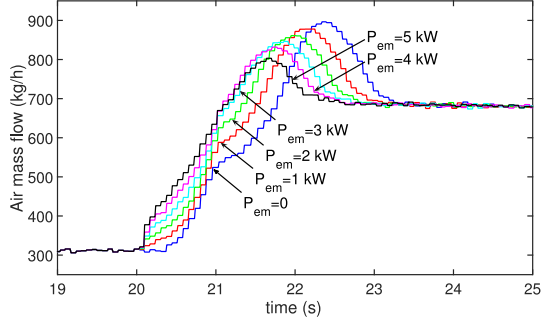

(b)

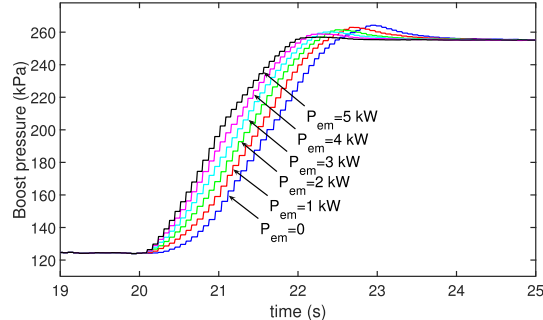

(c)

Fig. 3. Transient performance evaluation from $(1800 \mathrm{r} / \mathrm{min}, 100 \mathrm{~N} \cdot \mathrm{m})$ to $(1800 \mathrm{r} / \mathrm{min}, 800 \mathrm{~N} \cdot \mathrm{m}) .(\mathrm{a}) \omega \cdot$ (b) $W_{c}$. (c) $p_{\text {in }}$.

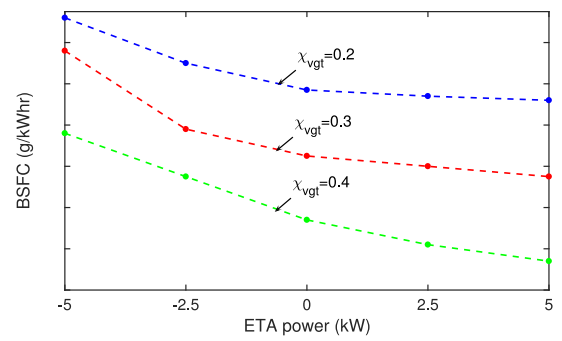

(a)

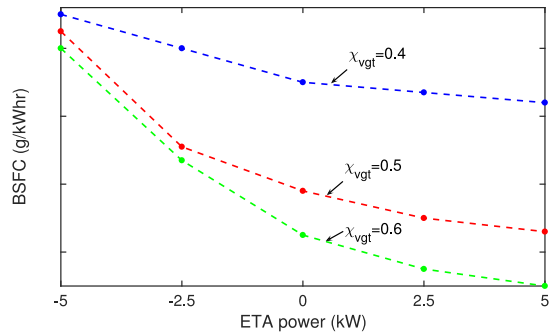

(d)

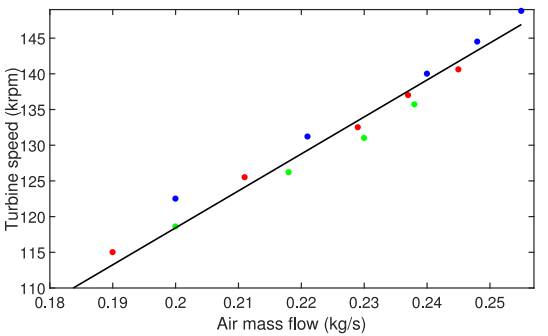

(g)

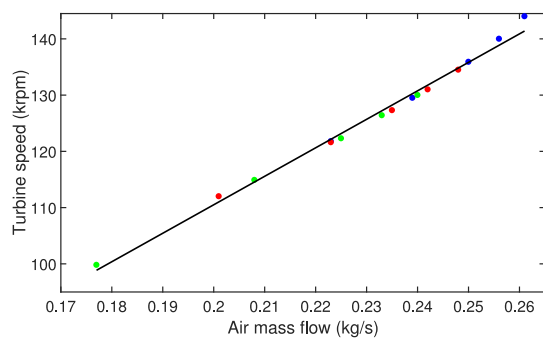

(j)

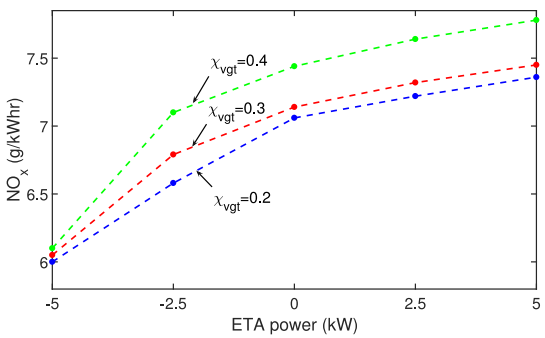

(b)

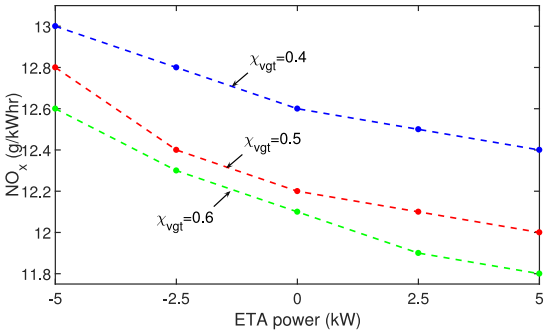

(e)

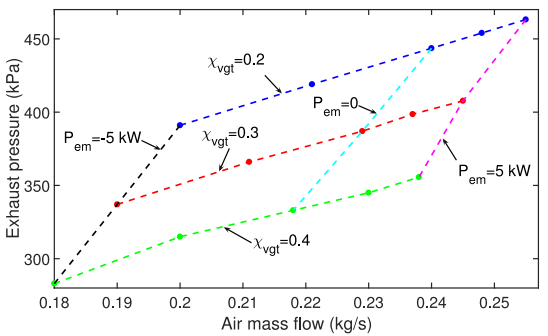

(h)

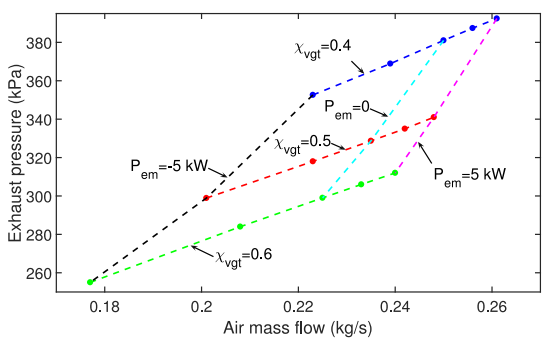

(k)

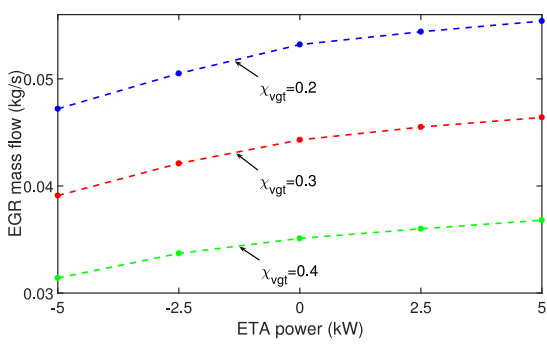

(c)

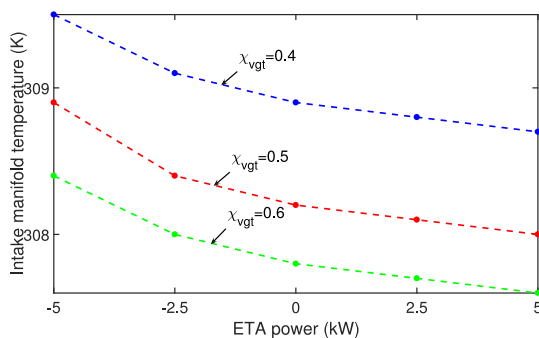

(f)

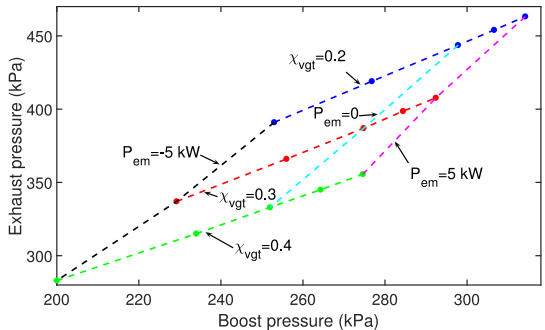

(i)

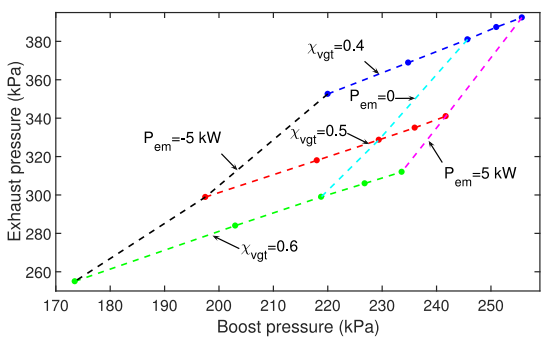

(1)

Fig. 4. System characterization at $(1800 \mathrm{r} / \mathrm{min}, 800 \mathrm{~N} \cdot \mathrm{m})$. (a) BSFC at $\chi_{\text {egr }}=0.3$. (b) $\mathrm{NO}_{x}$ at $\chi_{\text {egr }}=0.3$. (c) $W_{\text {egr }}$ at $\chi$ egr $=0.3$. (d) BSFC at $\chi_{\text {egr }}=0$. . (e) $\mathrm{NO}_{x}$ at $\chi_{\text {egr }}=0$. (f) $T_{\text {in }}$ at $\chi_{\text {egr }}=0$. (g) $\omega$ and $W_{c}$ at $\chi_{\text {egr }}=0.3$. (h) $p_{\text {exh }}$ and $W_{c}$ at $\chi_{\text {egr }}=0.3$. (i) $p_{\text {exh }}$ and $p_{\text {in }}$ at $\chi$ egr $=0.3$. (j) $\omega$ and $W_{c}$ at $\chi_{\text {egr }}=0 .(\mathrm{k}) p_{\mathrm{exh}}$ and $W_{c}$ at $\chi_{\mathrm{egr}}=0 .(\mathrm{I}) p_{\mathrm{exh}}$ and $p_{\text {in }}$ at $\chi$ egr $=0$. 
both increase, leading to the reduction in pumping and mechanical efficiency. Although the increased AFR can raise thermal efficiency, the overall fuel efficiency still decreases [18].

2) Analysis on Exhaust Emissions: The reduction of $\mathrm{NO}_{x}$ is the most critical topic in the latest exhaust emission legislation. To reduce $\mathrm{NO}_{x}$, the key approach is to reduce the peak combustion temperatures. There is a well-known "BSFC - $\mathrm{NO}_{x}$ " tradeoff, as can be observed from Fig. 4(b). When $P_{\mathrm{em}}$ is fixed, $\mathrm{NO}_{x}$ declines when $\chi_{\mathrm{vgt}}$ is more closed. This is due to the closing $\chi_{\mathrm{vgt}}$ leading to more $W_{\text {egr }}$ and the dilution of the fresh air and therefore, the combustion process is slowed down and the peak combustion temperature is reduced, as shown in Fig. 4(c). When $\chi_{\mathrm{vgt}}$ is fixed, $\mathrm{NO}_{x}$ increases when $P_{\mathrm{em}}$ moves from generating to motoring, which is driven by more fresh air being delivered into the intake manifold and the consequent combustion temperature increases. In the case of no $W_{\text {egr }}$, the trend changes, as shown in Fig. 4(e). The average $\mathrm{NO}_{x}$ increases significantly because there is no exhaust gas dilution. When $P_{\mathrm{em}}$ is fixed and $\chi_{\mathrm{vgt}}$ closes, $\mathrm{NO}_{x}$ increases because of better fresh air delivery. However, when $\chi_{\mathrm{vgt}}$ is fixed and EM shifts from generating to motoring, $\mathrm{NO}_{x}$ declines. This is because the $P_{\mathrm{em}}$ is converted by the compressor into increased boost, as shown in Fig. 4(h) and (k). This increases the AFR and improves the closed cycle efficiency which reduces the BSFC. There is a reduction in $T_{\mathrm{in}}$, as shown in Fig. 4(f), which contributes to the decline in $\mathrm{NO}_{x}$.

3) Analysis on Controllability: The EM provides an additional degree of freedom in engine air system control but also makes control more complicated. In a conventional TDE, the main target of air system control is reducing $\mathrm{NO}_{x}$ and PM. From a control point of view, the target can be achieved by regulating $p_{\text {in }}$ and $W_{c}$ [19]-[21]. However, in the ETDE, maximizing the fuel efficiency is an additional target and therefore, one more independent output has to be introduced. At a specific engine operating point, the dynamic model (1) needs to be linearized as linear state space equations to facilitate the use of existing control strategies. Therefore, the control problem is formulated as

$$
\left\{\begin{array}{l}
\dot{x}=A x+B u \\
y=C x
\end{array}\right.
$$

where $\boldsymbol{x} \in \mathbb{R}^{n}, \boldsymbol{u} \in \mathbb{R}^{3}$, and $\boldsymbol{y} \in \mathbb{R}^{3}$ are the state vector, input vector, and output vector, respectively; $\boldsymbol{A}, \boldsymbol{B}$, and $\boldsymbol{C}$ are coefficient matrices. It is required that (2) is controllable. In other words, the variables in $\boldsymbol{x}$ should be linearly independent. The selection of $\boldsymbol{x}$ are supported by the dynamic analysis. Strong couplings exist between the intake manifold and the turbine shaft, which can be explained by physics. The enthalpy in the exhaust gas speeds up the turbine, which is a relatively slow process. The rotational motion of the compressor blades transfers this kinetic energy to the fresh air, which is a fast process. As illustrated in Fig. 4(g) and (h), there is an almost linear relation between $W_{c}$ and $\omega$. Therefore, $\omega$ cannot be selected as the output due to the linear dependence. As a comparison, Fig. 4(h) and (k) show $p_{\text {exh }}$ is well decoupled from $W_{c}$ according to different settings on both $\chi_{\mathrm{vgt}}$ and $P_{\mathrm{em}}$. It also can be observed from Fig. 4(i) and (1) that $p_{\text {exh }}$ and $p_{\text {in }}$ are linearly independent. This proves the EM decouples the exhaust manifold and the intake

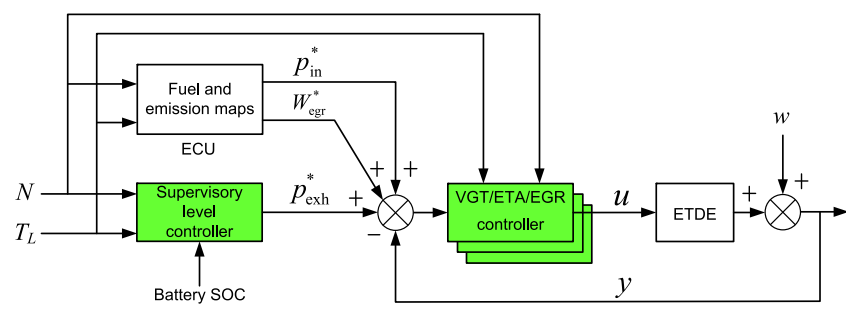

Fig. 5. Control structure of the ETDE.

manifold. As a consequence, the outputs in the ETDE should be chosen as $p_{\text {in }}, p_{\text {exh }}$, and $W_{c}$. In the steady state or slow transients, $W_{c}+W_{\text {egr }}=W_{e}$ is held and $W_{e}$ can be computed by $W_{e}=\eta_{v} p_{\text {in }} V_{d} N /\left(120 T_{\text {in }} R_{g}\right)$, so $W_{c}$ can be replaced by $W_{\text {egr }}$ [22]. As a summary, the physical states, inputs, and outputs are selected as

$$
\begin{aligned}
& \boldsymbol{x}=\left[p_{\text {in }}, p_{\text {exh }}, W_{\text {egr }}\right]^{\mathrm{T}} \\
& \boldsymbol{u}=\left[\chi_{\mathrm{vgt}}, P_{\mathrm{em}}, \chi_{\mathrm{egr}}\right]^{\mathrm{T}} \\
& \boldsymbol{y}=\left[p_{\text {in }}, p_{\text {exh }}, W_{\text {egr }}\right]^{\mathrm{T}}
\end{aligned}
$$

and thereafter (2) is guaranteed to be a controllable system.

\section{Multivariable Controller Design}

In a conventional TDE, $p_{\text {in }}$ and $W_{c}$ are controlled by $\chi_{\mathrm{vgt}}$ and $\chi_{\text {egr }}$ separately. In the ETDE, the connected targets of maximizing fuel economy and minimizing exhaust emissions require a more organized control of the augmented actuators. This requires consideration of both internal couplings and external disturbances. The control structure of the ETDE is to be built as Fig. 5. The ETDE has been characterized by nonlinear dynamics. A supervisory level controller behaves as the energy management module to generate the setpoint $p_{\text {exh }}^{*}$ in real time. The other two setpoints, $p_{\text {in }}^{*}$ and $W_{\text {egr }}^{*}$, are exported from the ECU according to offline calibration.

\section{A. Control Problem Formulation}

The transfer function from $\boldsymbol{y}^{*}$ to $\boldsymbol{y}$ is denoted as $G(s)$. The transfer function from the noise $w$ to $\boldsymbol{y}$ is denoted as $S(s)$, where $w$ is caused by vibration and heat release. $G(s)$ and $S(s)$ are expressed as

$$
\begin{aligned}
& G(s)=K(s) P(s) /(1+K(s) P(s)) \\
& S(s)=1 /(1+K(s) P(s))
\end{aligned}
$$

where $K(s)$ and $P(s)$ are the multivariable controller and linearized ETDE model, respectively. When the engine runs in a dynamic profile, $K(s)$ is gain scheduled in different speedload regions. The open-loop transfer function is denoted as $L(s)=K(s) P(s)$. It is expected that $K(s)$ can achieve both accurate tracking and high robustness in the face of $w$. The reference commands are mainly low frequency signals and noises are mainly high frequency. Since $G(s)+S(s) \equiv 1$ is held, designing $K(s)$ is translated to the design of $L(s)$ such that $|L(s)| \gg 1$ in low frequencies and $|L(s)| \ll 1$ in high frequencies. In other 


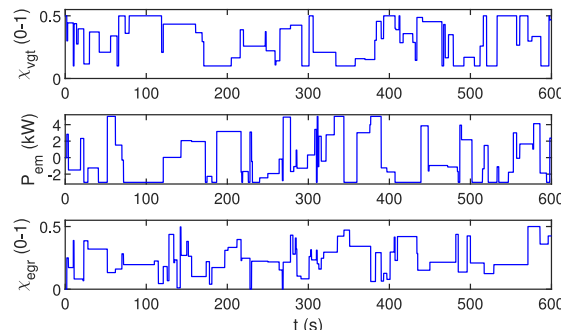

(a)

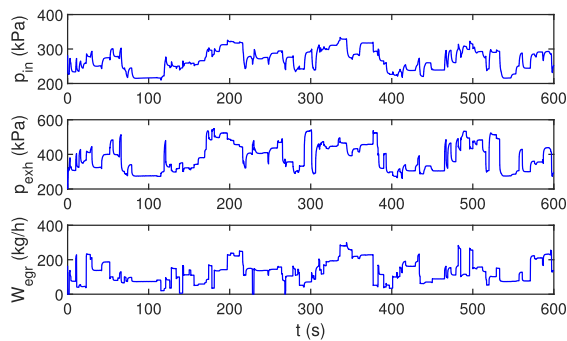

(b)

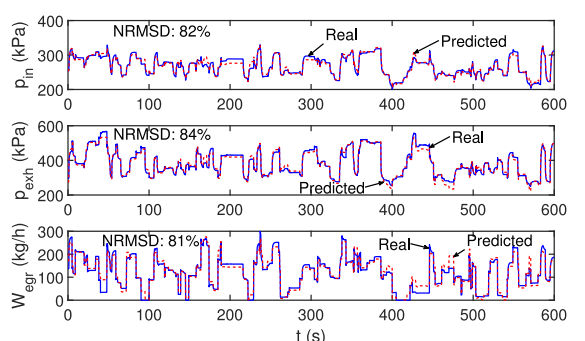

(c)

Fig. 6. Training and validation data at $(1800 \mathrm{r} / \mathrm{min}, 800 \mathrm{~N} \cdot \mathrm{m})$ for model identification. (a) Inputs of the training data. (b) Outputs of the training data. (c) Outputs of the validation data.

words, designing $K(s)$ is transferred to design a suitable $L(s)$ with the specified crossover frequency $\omega_{c}$. The control problem should be solved in two steps. First, a prefilter $W(s)$ is to be designed such that $\sigma\left(P_{s}(s)\right) \approx \sigma\left(P_{d}(s)\right)$ is held in a specific frequency range $\omega \in\left[\omega_{\min }, \omega_{\max }\right]$, where $P_{s}(s)=W(s) P(s)$ is the shaped ETDE model, $P_{d}(s)$ is the desired profile, and $\sigma$ denotes the singular values. Then, a desired controller $K_{d}(s)$ should be designed over $P_{s}(s)$ to balance tracking and robustness. The final controller is built as $K(s)=K_{d}(s) W(s)$.

\section{B. Model Identification}

The ETDE linear model $P(s)$ is identified from the time domain data. The general procedure of model identification includes model training and validation. Two groups of experimental calibration data $(\boldsymbol{u}(t), \boldsymbol{y}(t))$ are generated independently, which are treated as training set and validation set, respectively. The model is identified from the training set. Then, $\boldsymbol{u}(t)$ in the validation set is applied to the identified model to produce predicted outputs. As an example, two calibrations were made at $(1800 \mathrm{r} / \mathrm{min}, 800 \mathrm{~N} \cdot \mathrm{m})$. Both the calibrations have continued for $600 \mathrm{~s}$, whereas the action ranges of $\chi_{\mathrm{vgt}}, P_{\mathrm{em}}$, and $\chi_{\mathrm{egr}}$ are limited as [0.1, 0.5], [-3 kW, $5 \mathrm{~kW}]$, and [0, 0.5], respectively. The iterative ssest algorithm is employed to identify the model. The NRMSD is introduced to quantify the fitting results, and the model with a good NRMSD value would be selected. For the $i$ th variable in $\boldsymbol{y}$, the NRMSD value is defined as

$$
F(i)=1-\frac{\sqrt{\sum_{j=1}^{m}\left(y_{v}(i, j)-y_{p}(i, j)\right)^{2}}}{\sqrt{\sum_{j=1}^{m}\left(y_{v}(i, j)-\bar{y}_{v}(i)\right)^{2}}}, \quad i=1,2,3
$$

where $y_{v}$ is the validation data, $y_{p}$ is the predicted data, $\bar{y}_{v}(i)$ is the mean value of $y_{v}(i)$, and $m$ is the number of data samples. Model validation results are given in Fig. 6.

\section{Controller Synthesis}

The controller is synthesized using the perturbed normalized coprime factorization method developed by McFarlane and Glover [23]. Using the method, the shaped plant model can be represented by

$$
P_{s}(s)=M(s)^{-1} N(s)
$$

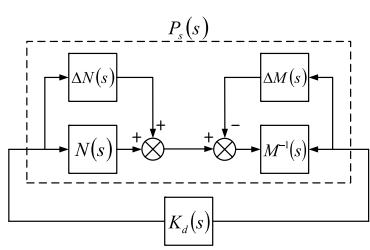

(a)

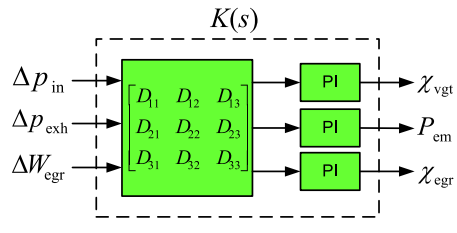

(b)
Fig. 7. Multivariable controller synthesis. (a) Reformulation of $P_{s}(s)$. (b) $K(s)$ in real-time control.
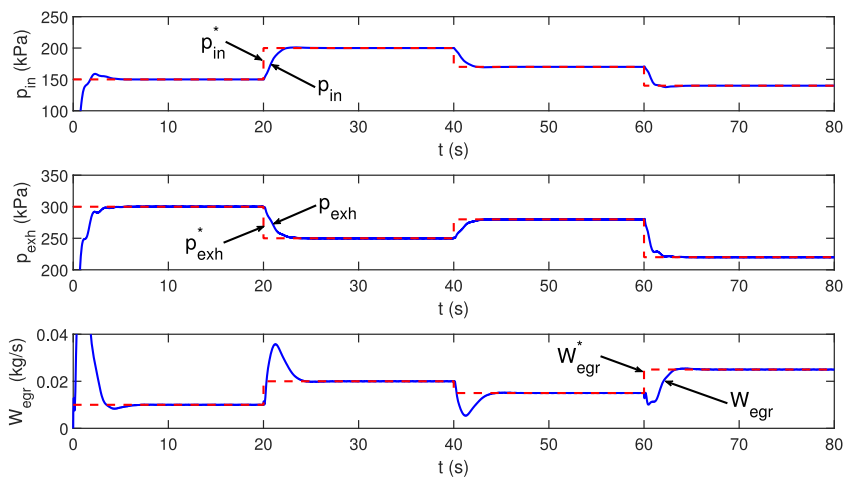

Fig. 8. Tracking performance at $(1800 \mathrm{r} / \mathrm{min}, 800 \mathrm{~N} \cdot \mathrm{m})$ in simulation.

where $M(s) M(s)^{*}+N(s) N(s)^{*}=I$, in which $M(s)^{*}=$ $[M(-s)]^{\mathrm{T}}$. The explicit forms of $M(s)$ and $N(s)$ can be found in [24]. The shaped plant with disturbances is represented by

$$
P_{s}(s)_{\Delta}=(M(s)+\Delta M(s))^{-1}(N(s)+\Delta N(s))
$$

as shown in Fig. 7(a). The disturbed system is stable if

$$
\|\Delta M(s), \Delta N(s)\| \leq \varepsilon_{\max }
$$

is held, with $\varepsilon_{\max }=\left(1-\|M(s), N(s)\|_{\mathrm{H}}^{2}\right)^{0.5}$, where $\|\cdot\|_{\mathrm{H}}$ denotes the Hankel norm. According to [25], (7) can be rewritten as designing a $H_{\infty}$ optimal controller $K_{d}(s)$ such that

$$
\left\|\begin{array}{c}
K_{d}(s)\left(1-P_{s}(s) K_{d}(s)\right)^{-1} M(s)^{-1} \\
\left(1-P_{s}(s) K_{d}(s)\right)^{-1} M(s)^{-1}
\end{array}\right\| \leq 1 / \varepsilon_{\max }
$$

is held. Now the controller synthesis is transformed to designing $K_{d}(s)$ that satisfies (8). The looptune solver in MATLAB is used to synthesize $K(s)$, by which the designer is greatly 


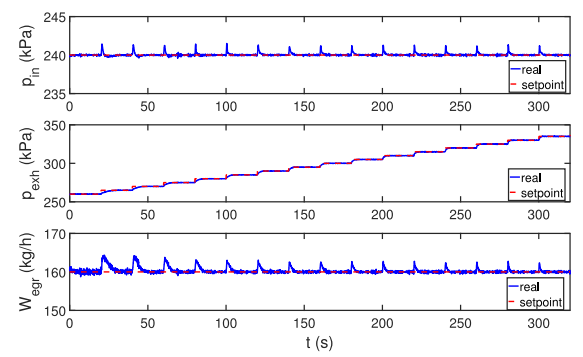

(a)

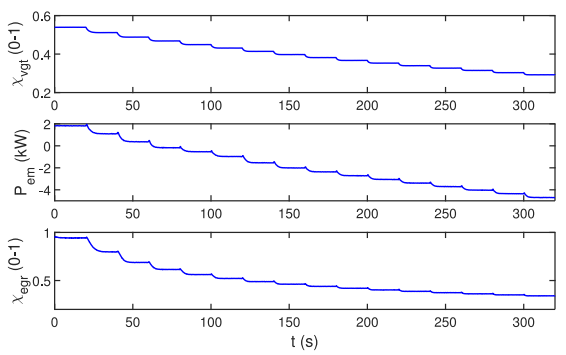

(b)

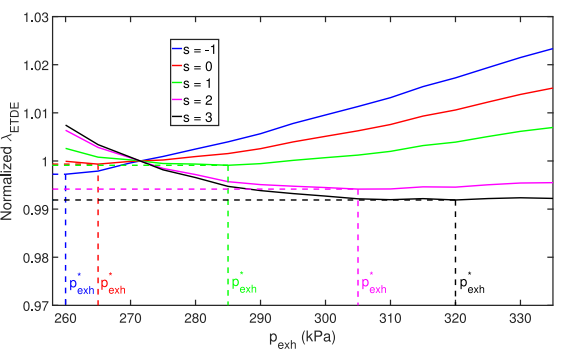

(c)

Fig. 9. Offline calibration at (1800 $\mathrm{r} / \mathrm{min}, 800 \mathrm{~N} \cdot \mathrm{m})$ and the online adaptation of $p_{\text {exh }}^{*}$ with variable $s(\mathrm{SOC})$. (a) Setpoints tracking. (b) Actuators action. (c) $s$ (SOC) and $p_{\text {exh }}^{*}$.

relieved from the nontrivial efforts of shaping the desired profile. The solver combines the Le-Safonov prefilter to tune the weight $W(s)$ and the Glover-McFarlane loop shaping technique to generate $K_{d}(s)$. The control problem is simplified to designing the desired crossover frequencies range. In implementation, $K(s)$ is expressed as a third-order decoupling matrix $D$ and three PI controllers working in series, as illustrated in Fig. 7(b). $D$ and gain values of PI controllers are built by looptune $\left(G(s), \omega_{c}\right)$. As an example, $K(s)$ at $(1800 \mathrm{r} / \mathrm{min}, 800 \mathrm{~N} \cdot \mathrm{m})$ is generated by setting $\omega_{c} \in[1 \mathrm{rad} / \mathrm{s}, 10 \mathrm{rad} / \mathrm{s}]$. The controller has been verified at different settings of setpoints, while the tracking results are shown as in Fig. 8. For all command signals, the tracking is fast and accurate in spite of multiple profiles on the outputs. When step changes occur on command signals, $p_{\text {in }}$ and $p_{\text {exh }}$ track smoothly whereas $W_{\text {egr }}$ tracks with small and short spikes, all converge in $3 \mathrm{~s}$. The outputs follow the multiple trajectories in a systematic manner. The simulation results validate the effectiveness of the synthesized controller and build the confidence in real testing.

\section{Supervisory LeVEL CONTROLleR Design}

The supervisory level controller is to optimize $p_{\mathrm{exh}}^{*}$ while maintaining the balance of battery SOC. The design process composes an offline stage and an online stage.

\section{A. Control Problem Formulation}

The compressor power is provided by both the turbine and the EM, so the following equation holds:

$$
P_{c}=P_{t}+P_{\mathrm{em}}
$$

The ETA works as a hybrid system, whose equivalent power is defined by

$$
P_{\mathrm{eq}}=P_{t}+s(\mathrm{SOC}) P_{\mathrm{em}}
$$

where $s(\mathrm{SOC})$ is an equivalent factor to perform as a necessary penalty on battery SOC deviation. The BSFC of the ETDE is quantified by $\lambda_{\mathrm{ETDE}}=\lambda_{e} P_{\mathrm{eq}} / P_{t}$, where $\lambda_{e}$ is the traditional BSFC defined by $\lambda_{e}=W_{f} / P_{b}$. $\lambda_{\text {ETDE }}$ is selected as the cost function and therefore, the online optimization problem is

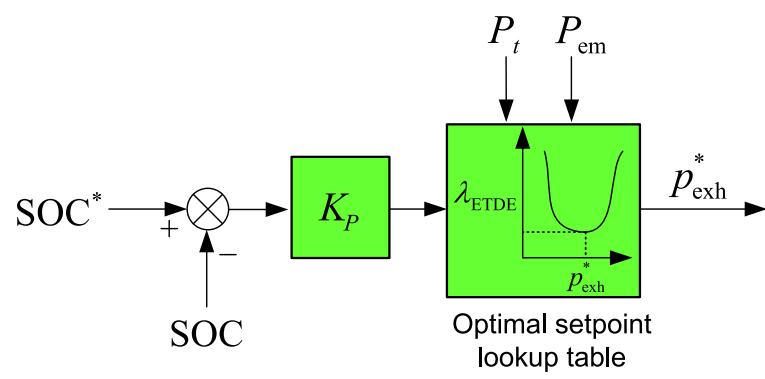

Fig. 10. Diagram of the supervisory level controller.

formulated as

$$
\begin{array}{ll}
\min _{\boldsymbol{u}}: & J(\boldsymbol{u})=\lambda_{\mathrm{ETDE}} \\
\text { s.t. : } & \boldsymbol{u}_{\min } \leq \boldsymbol{u} \leq \boldsymbol{u}_{\max }
\end{array}
$$

where the limits on $\boldsymbol{u}$ indicate the permissible actuator ranges.

\section{B. Offline Search}

The values of $p_{\mathrm{in}}^{*}$ and $W_{\mathrm{egr}}^{*}$ can be read from calibration results stored in ECU. Only $p_{\text {exh }}^{*}$ is to be generated by the supervisory level controller. An offline search is implemented, where $p_{\mathrm{exh}}^{*}$ is set as an incrementally increasing series. The developed $H_{\infty}$ multivariable controller in Section III is used to track the updating $p_{\mathrm{exh}}^{*}$. The value of $p_{\mathrm{exh}}^{*}$ is feasible only if it can be tracked well in the allowed actuator ranges. Fig. 9(a) shows the searching process at $(1800 \mathrm{r} / \mathrm{min}, 800 \mathrm{~N} \cdot \mathrm{m})$ in physical simulations, whereas $p_{\text {exh }}^{*}$ starts from $260 \mathrm{kPa}$, which is the minimum value to keep the engine stable. $p_{\mathrm{exh}}^{*}$ increases with the incremental pace of $5 \mathrm{kPa}$ every $20 \mathrm{~s}$. $p_{\text {in }}^{*}$ and $W_{\text {egr }}^{*}$ are maintained as $240 \mathrm{kPa}$ and $160 \mathrm{~kg} / \mathrm{h}$, respectively. As observed in Fig. 9(b), the physical upper boundary of $p_{\text {exh }}^{*}$ is $335 \mathrm{kPa}$, since $P_{\mathrm{em}}$ approaches the maximum generating power $-5 \mathrm{~kW}$ at this $p_{\mathrm{exh}}^{*}$ value. At each step of $p_{\mathrm{exh}}^{*}$, the value of $\lambda_{e}$, $P_{t}$, and $P_{\mathrm{em}}$ are recorded to compute $\lambda_{\mathrm{ETDE}}$. For instance, in the case of $p_{\text {exh }}^{*}=260 \mathrm{kPa}$, the three values are $209.5 \mathrm{~g} / \mathrm{kWh}$, $22.9 \mathrm{~kW}$, and $1.4 \mathrm{~kW}$, respectively. In different testing conditions, the upper boundary of $p_{\mathrm{exh}}^{*}$ can be tuned to track SOC ${ }^{*}$ at the end of testing cycles, where $\mathrm{SOC}^{*}$ is the desired SOC value. 


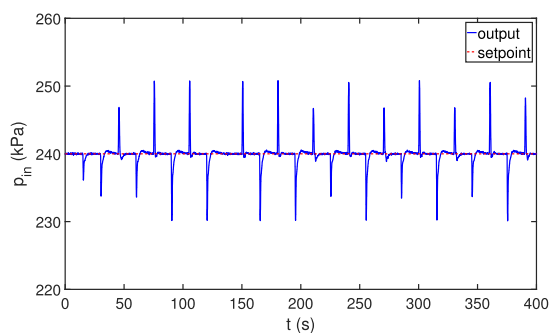

(a)

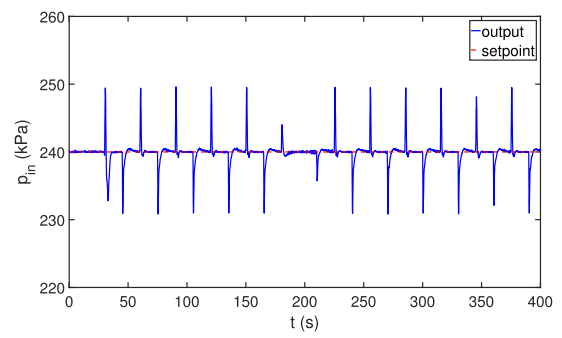

(d)

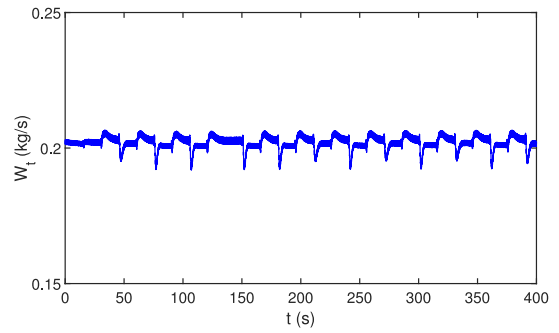

(g)

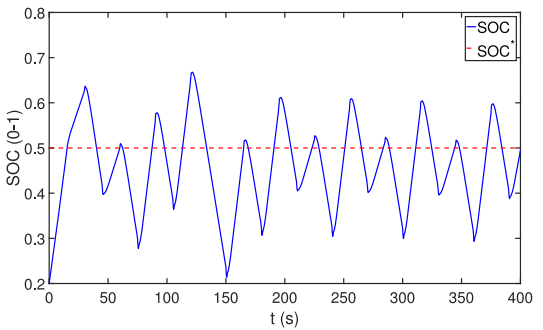

(j)

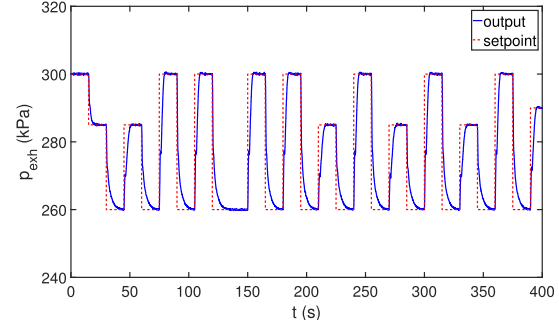

(b)

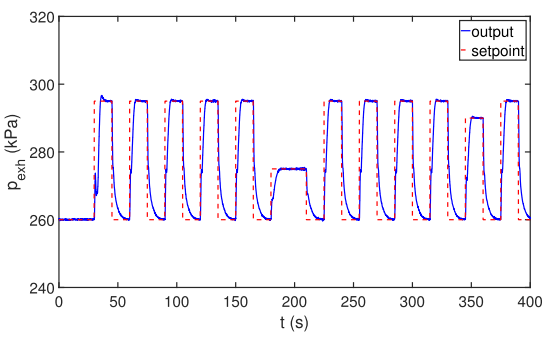

(e)

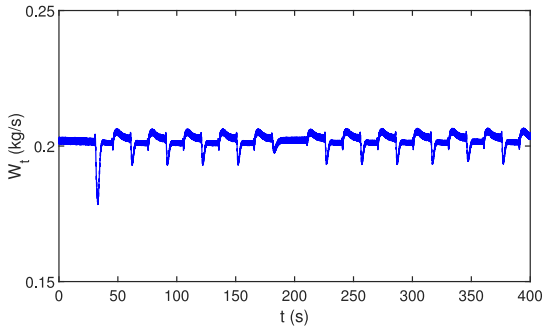

(h)

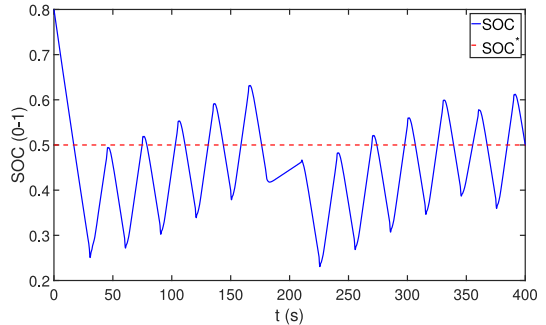

(k)

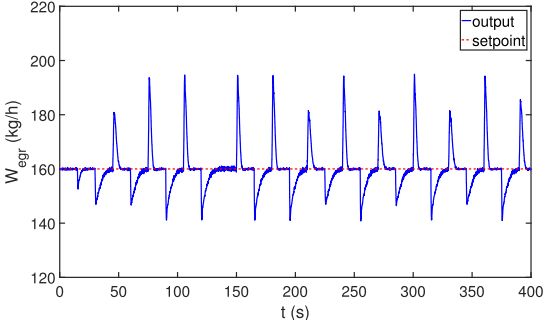

(c)

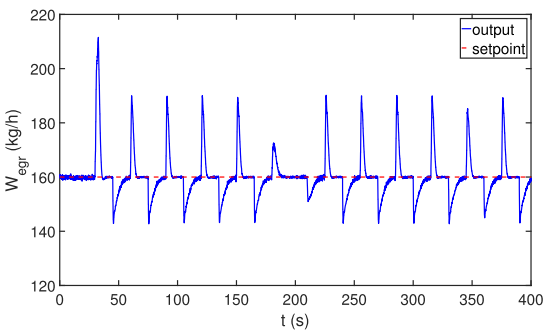

(f)
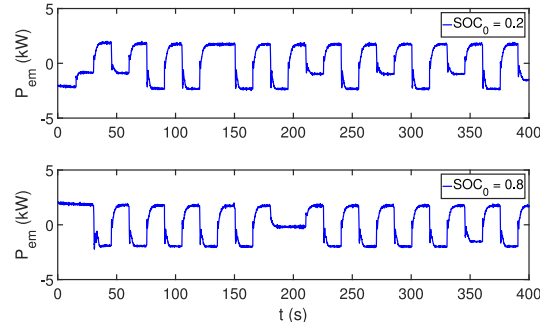

(i)

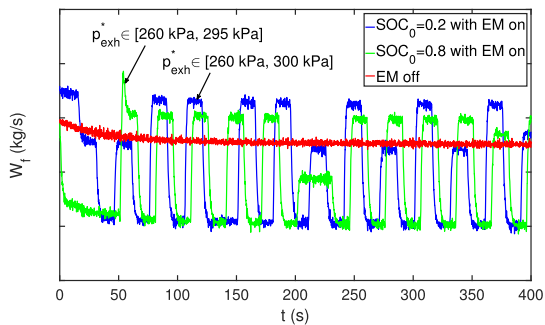

(1)

Fig. 11. Evaluation of system performance, battery SOC regulation, and fuel economy benefits by utilizing the hierarchical control strategy. (a) $p_{\text {in }}$ tracking at $\mathrm{SOC}_{0}=0.2$. (b) $p_{\text {exh }}$ tracking at $\mathrm{SOC}_{0}=0.2$. (c) $W_{\text {egr }}$ tracking at $\mathbf{S O C}_{0}=0.2$. (d) $p_{\text {in }}$ tracking at $\mathrm{SOC}_{0}=0.8$. (e) $p_{\text {exh }}$ tracking at

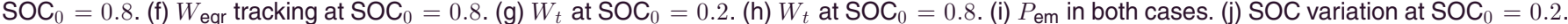
(k) $\mathrm{SOC}$ variation at $\mathrm{SOC}_{0}=0.8$. (I) fuel rate comparison.

\section{OnLine Optimization}

Based on the offline recorded $\lambda_{e}, P_{t}$, and $P_{\mathrm{em}}$, the value of $p_{\text {exh }}^{*}$ varies according to different $s$ settings. As shown in Fig. 9(c), when $s$ increases, $p_{\text {exh }}^{*}$ increases as well, shown more exhaust gas power would be recovered by the ETA. In the case of $s=0, p_{\mathrm{exh}}^{*}$ is $265 \mathrm{kPa}$ and the corresponding $P_{\mathrm{em}}$ is $0.8 \mathrm{~kW}$. It indicates the ETDE tends to run the ETA in motoring mode when battery SOC is not a concern. The deviation of SOC is essential to be revealed in online optimization. The equivalent factor in (10) is designed as

$$
s(\mathrm{SOC})=K_{P} \Delta \mathrm{SOC}
$$

where $K_{P}$ is a positive constant, and $\triangle \mathrm{SOC}=\mathrm{SOC}-\mathrm{SOC}^{*}$. At different $\mathrm{SOC}$ values, $P_{t}$ and $P_{\mathrm{em}}$ have different weightings on the cost function $\lambda_{\mathrm{ETDE}}$, and the optimal $p_{\mathrm{exh}}^{*}$ is read from the lookup table that corresponds to the minimal $\lambda_{\text {ETDE }}$. The designed supervisory level controller is illustrated in Fig. 10.

\section{Controller Evaluation}

The two-level control strategy was validated in physical simulations. The controller was built in Simulink and a high-fidelity ETDE physical model was built in Dynasty, a proprietary multiphysics simulation software package developed by Caterpillar Inc. At (1800 r/min, $800 \mathrm{~N} \cdot \mathrm{m})$, two cases were evaluated for $400 \mathrm{~s}$, with the initial $\mathrm{SOC}$ values were set as $\mathrm{SOC}_{0}=0.2$ and $\mathrm{SOC}_{0}=0.8$, respectively. The EM-off mode was used as the baseline, whereas $p_{\text {in }}$ and $W_{\text {egr }}$ were controlled by $\chi_{\text {vgt }}$ and $\chi_{\text {egr }}$ using two SISO PID controllers. The gain value in the 


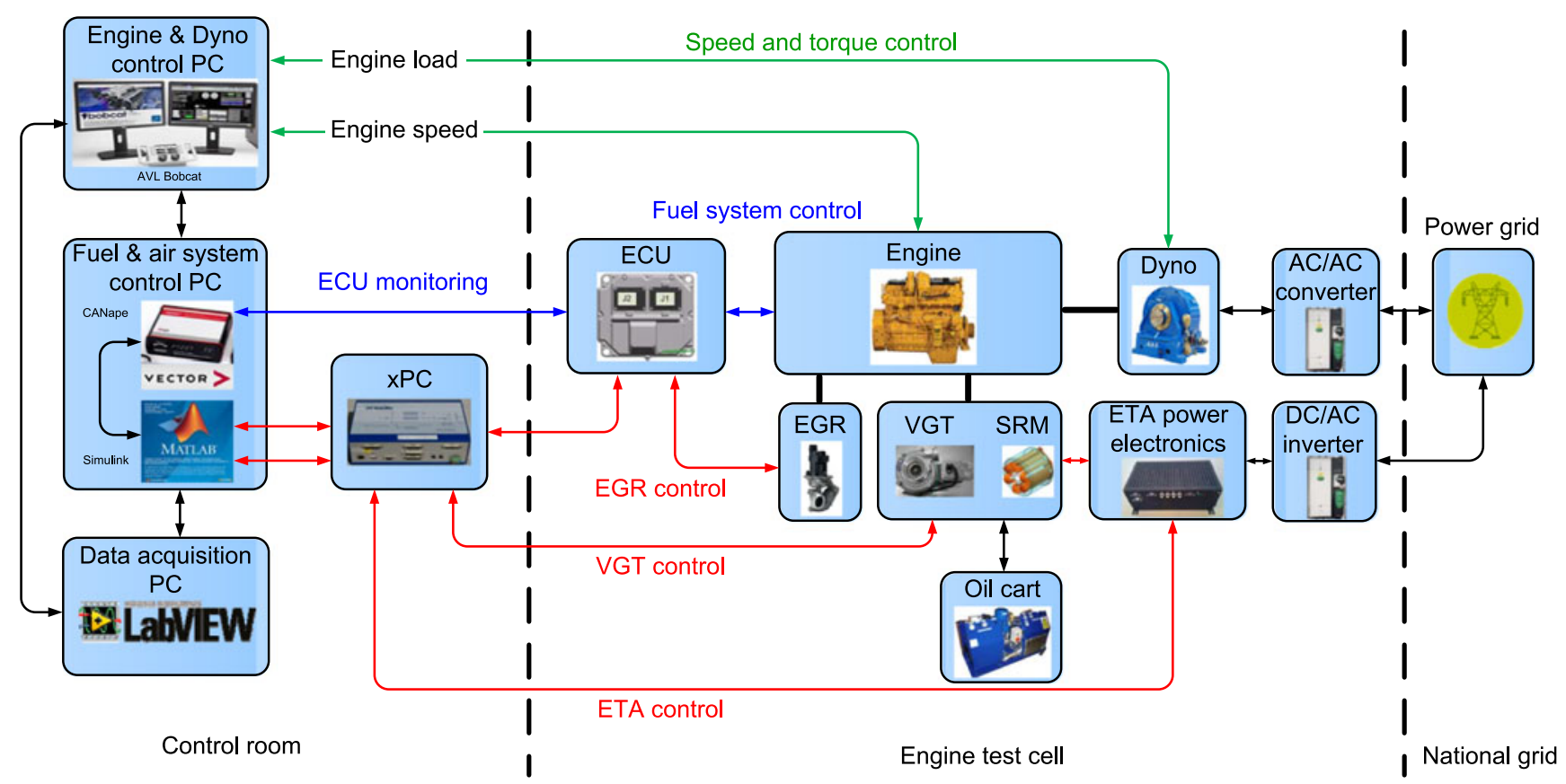

Fig. 12. Testing diagram of the electrified turbocharged diesel engine.

supervisory level controller was set as $K_{P}=2$. The tracking under $\mathrm{SOC}_{0}=0.2$ are shown in Fig. 11(a)-(c), whereas $p_{\text {in }}^{*}$ and $W_{\text {egr }}^{*}$ are maintained as constants. The tracking under $\mathrm{SOC}_{0}=0.8$ are shown in Fig. 11(d)-(f). Using the supervisory level controller, $p_{\mathrm{exh}}^{*}$ updates to achieve the minimum $\lambda_{\mathrm{ETDE}}$. The exhaust gas passes through the turbine are shown in Fig. 11(g)(h). The actions of $P_{\mathrm{em}}$ in both EM-on cases are shown in Fig. 11(i). Using the low level $H_{\infty}$ controller, the setpoints are all well tracked. The SOC is well recovered back to the desired value 50\% at the end of testing cycle, as shown in Fig. 11(j). Similarly, the SOC is also tracked back well to $\mathrm{SOC}^{*}$ in the case of $\mathrm{SOC}_{0}=0.8$, as shown in Fig. 11(k). $W_{f}$ in the three cases are shown in Fig. 11(1). In the EM-on mode of $\mathrm{SOC}_{0}=0.2$ and $\mathrm{SOC}_{0}=0.8$, the fuel consumption are $3.5623 \mathrm{~kg}$ and $3.5576 \mathrm{~kg}$, respectively. In the EM-off mode, the fuel consumption is $3.5829 \mathrm{~kg}$. The fuel economy benefits are $0.575 \%$ and $0.706 \%$, respectively. The fuel efficiency improvements are because the EM provides more flexibility in energy flow distribution. The control strategy can always drive the turbine to run in a more efficient zone, and the EM runs as an assist.

\section{Experiments Setup ANd Results}

\section{A. Experiments Setup}

The testing platform is based on a Cat C7.1 ACERT heavyduty off-highway diesel engine, as shown in Fig. 12. The engine produces up to $205 \mathrm{~kW}$ at its rated speed of $2200 \mathrm{r} / \mathrm{min}$, and provides a peak torque of $1257 \mathrm{~N} \cdot \mathrm{m}$ at $1400 \mathrm{r} / \mathrm{min}$. The engine is equipped with a high-pressure loop cooled EGR and an ETA. The ETA is developed based on a modified BorgWarner BV63 turbocharger, whereas the embedded SRM operates up to $140 \mathrm{kr} / \mathrm{min}$. The SRM is compact and the increased inertia of the ETA is less than $10 \%$. The engine is connected to a $480 \mathrm{~kW}$

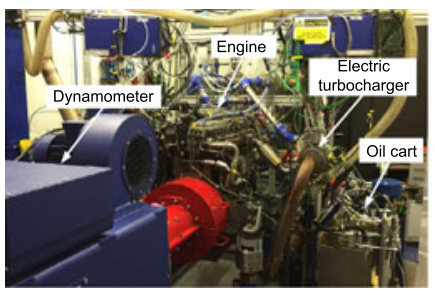

(a)

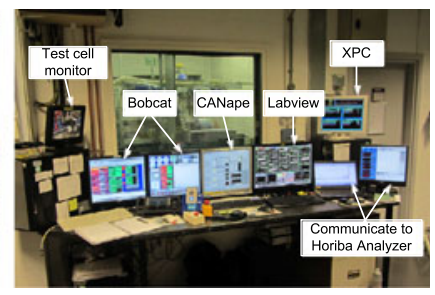

(b)
Fig. 13. Experimental setup of the electrified turbocharged diesel engine. (a) Instrumented engine. (b) Operation platform.

dynamometer capable of running fast transients. The exhaust gas emissions are measured using a Horiba 9000 DEGR analyzer.

The $N$ and $T_{L}$ are both controlled by AVL Bobcat software. The fuel system is controlled by the ECU, and visualized with Vector CANape software. The air system controller is built in Simulink, whereas the EGR control command is sent via the ECU, and the control commands of other actuators are sent via xPC. The ETA is oil-cooled using an oil cart and the acquired test data are recorded by AVL Bobcat. The xPC links to Vector CANape and MATLAB on the host PC with an Ethernet cable whereas all the other modules communicate via a CAN bus at a frequency of $50 \mathrm{~Hz}$. The pictures of the engine test cell and operation platform are shown in Fig. 13.

\section{B. Experimental Results}

1) Tracking Performance Under Steady State: The testing results at $(1800 \mathrm{r} / \mathrm{min}, 260 \mathrm{~N} \cdot \mathrm{m})$ are illustrated in Fig. 14. The tracking performance and control signals are illustrated in the first row and second row, respectively. From 0 to $160 \mathrm{~s}, p_{\text {in }}^{*}$ changes periodically between 160 and $130 \mathrm{kPa}$, whereas $p_{\text {exh }}^{*}$ and $W_{\text {egr }}^{*}$ are maintained at $195 \mathrm{kPa}$ and $110 \mathrm{~kg} / \mathrm{h}$, respectively. When $p_{\text {in }}^{*}$ drops, $\chi_{\text {vgt }}$ is more open to reduce $p_{\text {in }}$. Meanwhile, 


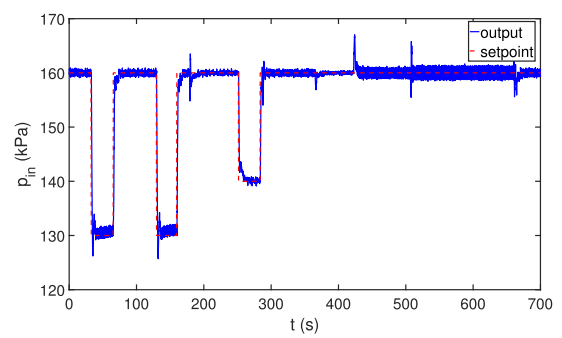

(a)

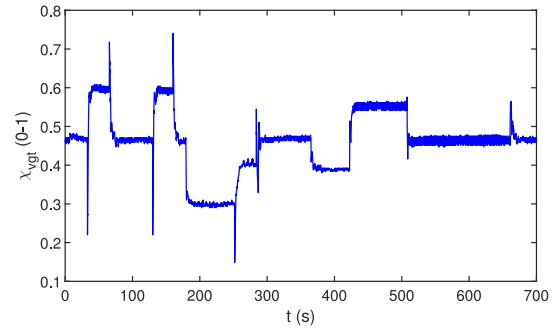

(d)

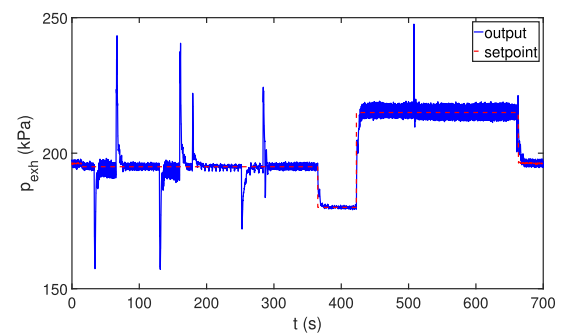

(b)

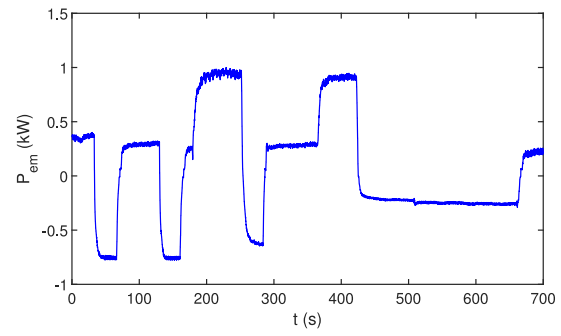

(e)

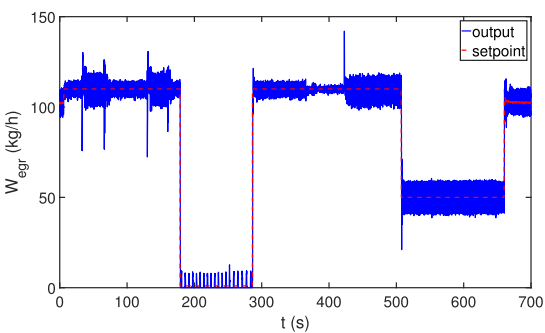

(c)

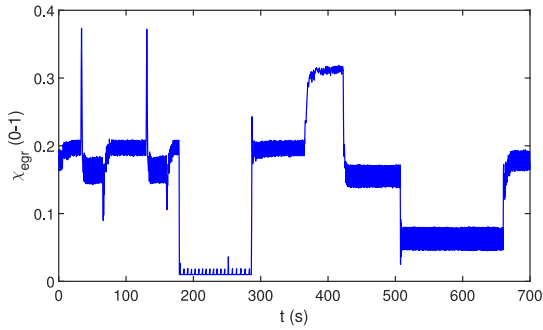

(f)

Fig. 14. Tracking performance test under variable setpoints at $(1800 \mathrm{r} / \mathrm{min}, 260 \mathrm{~N} \cdot \mathrm{m})$. (a) $p_{\text {in }}$ tracking. (b) $p_{\text {exh }}$ tracking. (c) $W_{\text {egr }}$ tracking. (d) $\chi_{\mathrm{vgt}}$ action. (e) $P_{\text {em }}$ action. (f) $\chi_{\text {egr }}$ action.

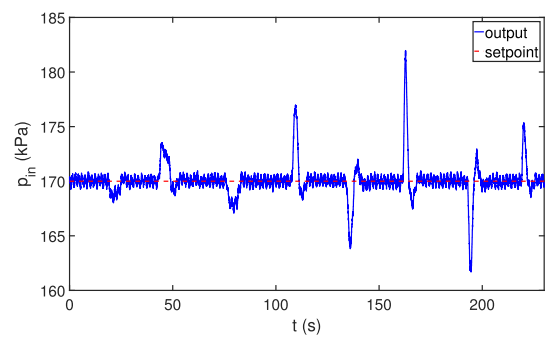

(a)

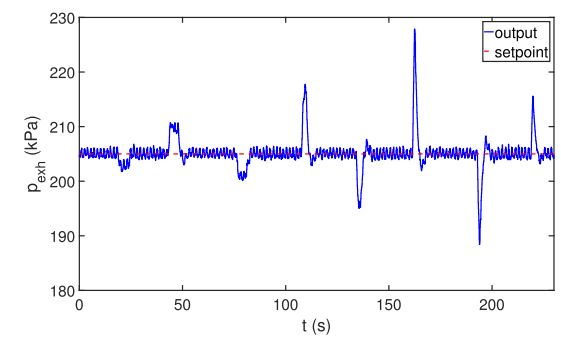

(b)

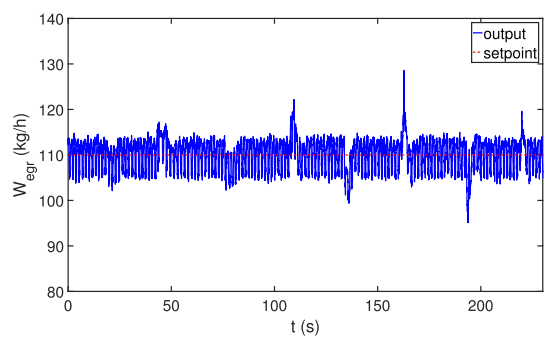

(c)

Fig. 15. Robustness test under operating point switches between $(1700 \mathrm{r} / \mathrm{min}, 400 \mathrm{~N} \cdot \mathrm{m})$ and $(1900 \mathrm{r} / \mathrm{min}, 400 \mathrm{~N} \cdot \mathrm{m})$. (a) $p_{\text {in }}$ tracking. (b) $p_{\text {exh }}$ tracking. (c) $W_{\text {egr }}$ tracking.

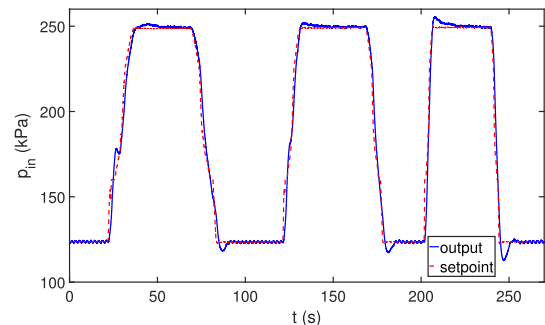

(a)

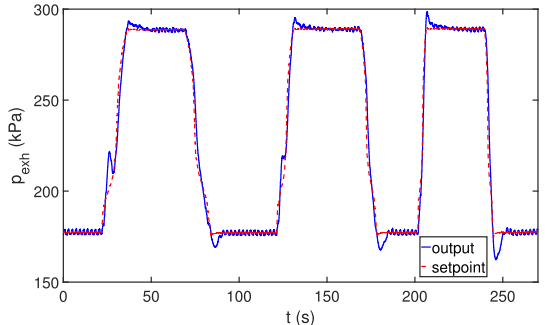

(b)

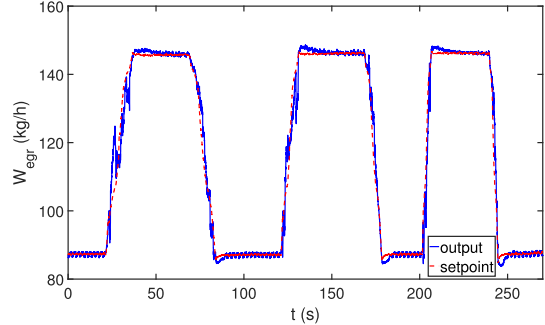

(c)

Fig. 16. Gain scheduling performance test under operating point switches between $(1800 \mathrm{r} / \mathrm{min}, 120 \mathrm{~N} \cdot \mathrm{m})$ and $(1800 \mathrm{r} / \mathrm{min}, 800 \mathrm{~N} \cdot \mathrm{m})$. (a) $p_{\text {in }}$ tracking. (b) $p_{\text {exh }}$ tracking. (c) $W_{\text {egr }}$ tracking.

EM switches from motoring to generating so as to reduce $\omega$ to prevent $p_{\text {exh }}$ reduction. $W_{\text {egr }}$ tends to increase since the gap between $p_{\text {exh }}$ and $p_{\text {in }}$ increases. As a result, $\chi_{\text {egr }}$ closes to maintain $W_{\text {egr. }}$ Similar phenomenon can also be observed at $250 \mathrm{~s}$ when $p_{\text {in }}^{*}$ drops from 160 to $140 \mathrm{kPa}$. At $180 \mathrm{~s}, W_{\mathrm{egr}}^{*}$ is set to a very small value close to zero, whereas $p_{\mathrm{in}}^{*}$ and $p_{\mathrm{exh}}^{*}$ are both maintained. $\chi_{\mathrm{egr}}$ is forced to saturate at its lower limit immediately. To restrain the increasing trend of $p_{\mathrm{exh}}, P_{\mathrm{em}}$ jumps to a high value to increase $\omega$. The lack of $W_{\text {egr }}$ reduces $p_{\text {in }}$ and therefore, $\chi_{\text {vgt }}$ closes to increase $p_{\text {in }}$. It is similar to the case when $W_{\text {egr }}^{*}$ drops from 110 to $50 \mathrm{~kg} / \mathrm{h}$ at $505 \mathrm{~s}$. At $365 \mathrm{~s}, p_{\text {exh }}^{*}$ drops from 195 to $180 \mathrm{kPa}$, whereas $p_{\text {in }}^{*}$ and $W_{\text {egr }}^{*}$ are both maintained. It forces EM to work at a higher motoring power to reduce $p_{\text {exh }}$. At the same time, $\chi_{\mathrm{vgt}}$ closes to maintain $p_{\text {in }}$. On the other hand, $\chi_{\text {egr }}$ reduces to maintain $W_{\text {egr }}$. All the outputs converge in $8 \mathrm{~s}$ when setpoints change. 
2) Robustness Against Disturbances: The tracking performance when disturbances are added on $N$ are illustrated in Fig. 15. The engine model was identified at $(1800 \mathrm{r} / \mathrm{min}$, $400 \mathrm{~N} \cdot \mathrm{m})$ but the operating point switches between $(1900 \mathrm{r} / \mathrm{min}$, $400 \mathrm{~N} \cdot \mathrm{m})$ and $(1700 \mathrm{r} / \mathrm{min}, 400 \mathrm{~N} \cdot \mathrm{m}) \cdot p_{\text {in }}^{*}, p_{\text {exh }}^{*}$, and $W_{\text {egr }}^{*}$ are set at $170 \mathrm{kPa}, 205 \mathrm{kPa}$, and $110 \mathrm{~kg} / \mathrm{h}$, respectively. All the setpoints are tracked very well at the beginning. When $N$ drops from 1900 to $1700 \mathrm{r} / \mathrm{min}$, all the outputs decrease suddenly because of the reduced engine power. Accordingly, the controller tunes the actuators quickly to adapt to the new dynamics. $\chi_{\mathrm{vgt}}$ increases to reduce $\omega$ and therefore $p_{\text {exh }}$ is raised. Meanwhile, $P_{\text {em }}$ increases to recover $p_{\text {in }}$ and $W_{\text {egr }}$. The switching of operating points causes spikes on outputs but all converge within $7 \mathrm{~s}$.

3) Gain Scheduling Under Transients: The gain scheduling performance was tested under block loads, where the operating point switches between $(1800 \mathrm{r} / \mathrm{min}, 120 \mathrm{~N} \cdot \mathrm{m})$ and $(1800 \mathrm{r} / \mathrm{min}, 800 \mathrm{~N} \cdot \mathrm{m})$ with variable ramping rates. Two controllers were built at the two points separately and a hard switching mechanism is employed. The testing results were shown in Fig. 16, where the torque ramping time is set as 10,5 , and $2 \mathrm{~s}$ in the three load blocks, respectively. $p_{\text {in }}^{*}, p_{\text {exh }}^{*}$, and $W_{\text {egr }}^{*}$ are set as $124 \mathrm{kPa}, 177 \mathrm{kPa}$, and $87 \mathrm{~kg} / \mathrm{h}$ at the low torque point, and $249 \mathrm{kPa}, 289 \mathrm{kPa}$, and $146 \mathrm{~kg} / \mathrm{h}$ at the high torque point. It is observed that the gain-scheduled-controller is very effective in precisely tracking the setpoints in both transients and steady state. The spikes on $p_{\text {in }}, p_{\text {exh }}$, and $W_{\text {egr }}$ are less than $6 \mathrm{kPa}, 8 \mathrm{kPa}$, and $3 \mathrm{~kg} / \mathrm{h}$, respectively.

\section{CONCLUSION}

An integrated framework for characterization, control, and testing of an electrical turbocharger assist was proposed in this paper. Characterization leads to a better understanding of both engine behavior and the selection of outputs for coordinated control. In such an augmented turbocharging system, the exhaust pressure setpoints were updated by a supervisory level controller to achieve the best fuel economy in real time. A model-based multivariable $H_{\infty}$ controller was analytically designed to track the setpoints in a coordinated way. A testing platform was established and the control strategy was tested. Testing results showed excellent tracking performance, high robustness, and promising fuel efficiency improvements. Future study includes applying the hybrid turbocharger and the control strategy on downsized engines. The second generation hybrid turbocharger called E-Turbo is also being evaluated.

\section{ACKNOWLEDGMENT}

Innovate U.K. is an executive body established by the U.K. Government to drive innovation. It promotes and invests in research, development, and the exploitation of science, technology, and new ideas for the benefit of business-increasing sustainable economic growth in the U.K. and improving quality of life.

\section{REFERENCES}

[1] O. Awad et al., "Using fusel oil as a blend in gasoline to improve SI engine efficiencies: A comprehensive review," Renew. Sustain. Energy Rev., vol. 69, pp. 1232-1242, 2017.
[2] W. Enang and C. Bannister, "Modelling and control of hybrid electric vehicles: A comprehensive review," Renew. Sustain. Energy Rev., vol. 74, pp. 1210-1239, 2017.

[3] A. Bin Mamat, R. Martinez-Botas, S. Rajoo, A. Romagnoli, and S Petrovic, "Waste heat recovery using a novel high performance low pressure turbine for electric turbocompounding in downsized gasoline engines," Energy, vol. 90, no. 1, pp. 218-234, 2015.

[4] L. Eriksson, T. Lindell, O. Leufven, and A. Thomasson, "Scalable component-based modeling for optimizing engines with supercharging, eboost and turbocompound concepts," SAE Int. J. Engines, vol. 5, pp. 579595, 2012.

[5] R. Salehi, J. Martz, A. Stefanopoulou, T. Hansen, and A. Haughton, "Comparison of high- and low-pressure electric supercharging of a HDD engine: steady state and dynamic air-path considerations," SAE Int., Warrendale, PA, USA, pp. 2016-01-1035, 2016.

[6] N. Okui, "A study on improvement of fuel economy of heavy duty hybrid truck with new type of hybrid electric assist engine system," SAE Int. J. Commercial Veh., vol. 9, pp. 41-50, 2016.

[7] H. Tran, B. Richard, K. Gray, and M. Bassett, "Developing a performance specification for an electric supercharger to satisfy a range of downsized gasoline engine applications," SAE Int. J. Commercial Veh., pp. 2016-011041, 2016.

[8] G. Pasini, "Evaluation of an electric turbo compound system for SI engines: A numerical approach," Appl. Energy, vol. 162, pp. 527-540, 2016.

[9] M. Kant, A. Romagnoli, A. Mamat, and R. Martinez-Botas, "Heavy-duty engine electric turbocompounding," Proc. Inst. Mech. Eng. D, J. Autom. Eng., vol. 229, no. 4, pp. 457-472, 2014.

[10] I. Thompson, S. Spence, D. Thornhill, and C. McCartan, "The technical merits of turbogenerating shown through the design, validation and implementation of a one-dimensional engine model," Int. J. Engine Res., vol. 15, no. 1, pp. 66-77, 2014.

[11] R. Baar and V. Boxberger, "Boosting technologies and limits for small combustion engines," SAE Int., Warrendale, PA, USA, pp. 2016-32-0077, 2016.

[12] H. Aghaali and H. Angstrom, "A review of turbocompounding as a waste heat recovery system for internal combustion engines," Renew. Sustain. Energy Rev., vol. 49, no. 1, pp. 813-824, 2015.

[13] M. Bailey, "Electrically-assisted turbocharger development for performance and emissions," in Proc. Diesel Engine Emissions Reduction Workshop, 2000, Art. no. 827803.

[14] S. Arnold et al., "Garrett electric boosting systems (EBS) program," Honeywell Turbo Technologies, Rolle, Switzerland, Tech. Rep. DE-FC0500OR22809, Jun. 2005.

[15] K. Shiraishi, Y. Ono, and Y. Yamashita, "Energy savings through electricassist turbocharger for marine diesel engines," Mitsubishi Heavy Industries Tech. Rev., vol. 52, no. 1, pp. 36-41, 2015.

[16] J. Bumby et al., "Electrical machines for use in electrically assisted turbochargers," in Proc. 2nd Int. Conf. Power Electr., Mach. Drives, 2004, pp. 344-349.

[17] X. Xue and J. Rutledge, "Potentials of electrical assist and variable geometry turbocharging system for heavy-duty diesel engine downsizing," SAE Int., Warrendale, PA, USA, Rep., pp. 2017-01-1035, 2017.

[18] E. Winward et al., "Performance testing of an electrically assisted turbocharger on a heavy duty diesel engine," in Proc. 12th Int. Conf. Turbochargers Turbocharging, 2016, pp. 1-22.

[19] U. Kalla, B. Singh, and S. Murthy, "Green controller for efficient diesel engine driven single-phase SEIG using maximum efficiency point operation," IEEE Trans. Ind. Electron., vol. 64, no. 1, pp. 264-274, Jan. 2017.

[20] W. Xue, W. Bai, S. Yang, K. Song, Y. Huang, and H. Xie, "ADRC with adaptive extended state observer and its application to air fuel ratio control in gasoline engines," IEEE Trans. Ind. Electron., vol. 62, no. 9, pp. 5847 5857, Sep. 2015

[21] R. Salehi, "A second-order sliding mode observer for fault detection and isolation of turbocharged SI engines," IEEE Trans. Ind. Electron., vol. 62, no. 12 , pp. 7795-7803, Dec. 2015.

[22] D. Zhao, C. Liu, R. Stobart, X. Deng, E. Winward, and G. Dong, "An explicit predictive control framework for turbocharged diesel engines," IEEE Trans. Ind. Electron., vol. 61, no. 7, pp. 3540-3552, Jul. 2014.

[23] D. McFarlane and K. Glover, "A loop shaping design procedure using $H_{\infty}$ synthesis," IEEE Trans. Autom. Control, vol. 37, no. 6, pp. 759-769, Jun. 1992.

[24] W. Wang, S. Engell, and R. Mueller,"Robust controller design by a combination of loop shaping and frequency response approximation," in Proc. 13th World Congr. IFAC, 1996, vol. 29, pp. 3731-3736.

[25] M. Vidyasagar and H. Kimura, "Robust controllers for uncertain linear multivariable systems," Automatica, vol. 22, no. 1, pp. 85-94, 1986. 


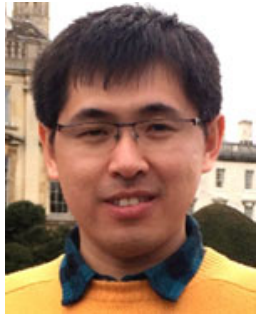

Dezong Zhao (M'12-SM'17) received the B.S and M.S. degrees in control science and engineering from the School of Control Science and Engineering, Shandong University, Jinan, China, in 2003 and 2006, respectively, and the $\mathrm{Ph} . \mathrm{D}$. degree in control science and engineering from the Department of Automation, Tsinghua University, Beijing, China, in 2010.

Since 2017, he has been a Lecturer in intelligent systems with the Department of Aeronautical and Automotive Engineering, Loughborough University, Loughborough, U.K. His research interests include artificial intelligence, autonomous vehicles, low carbon vehicles, and energy recovery systems.

Dr. Zhao was a recipient of the Excellence 100 Campaign of Loughborough University.

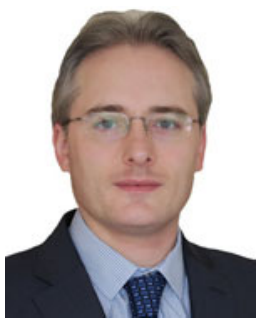

Edward Winward received the M.Eng degree (with first-class honors) in automotive engineering from Loughborough University and Ph.D. degree in the study of diesel engine exhaust soot physiochemical properties from Loughborough University, Loughborough, U.K., in 2003 and 2013, respectively.

$\mathrm{He}$ is currently a Senior Research Associate with the Department of Aeronautical and Automotive Engineering, Loughborough University.

His research interests include energy recovery systems, electrified ancillary systems, and innovative testing approaches for complex systems.

Dr. Winward a member of the U.K. Institution of Mechanical Engineers.

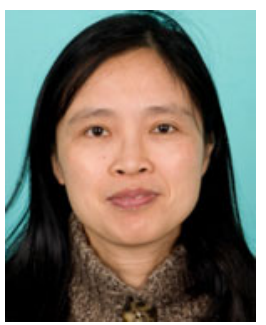

Zhijia Yang received the Ph.D. degree for the study of diesel engine control from Loughborough University, Loughborough, U.K., in 2013.

She is currently a Research Associate with the Department of Aeronautical and Automotive Engineering, Loughborough University. Her research interests include advanced automotive engine control, engine auto calibration, and engine waste thermal energy recovery.

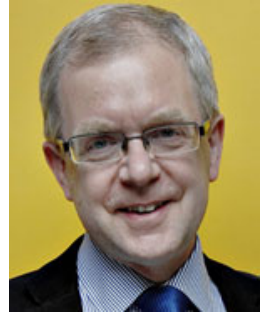

Richard Stobart (M'93) received the B.S (Hons.) degree in mechanical engineering from the University of Cambridge, Cambridge, U.K., in 1979.

From 1979 to 2001, he worked in commercial $R \& D$, when he was appointed as a Professor in automotive engineering at the University of Sussex, Brighton, U.K., where he was also the Head of Engineering and Design, from 2003 to 2006. In 2007, he was appointed as a Professor of automotive engineering at Loughborough University, and from 2008 to 2011 was Head of aeronautical and automotive engineering. In 2016, he retired from his full time position as a Professor of powertrain systems, and as a Professor Emeritus continues to work in research in the fields of energy recovery and engine control.

Prof. Stobart was a member of the team who, in 1997, was a recipient of the Arthur D Little Ketteringham Prize for innovation in the design of fuel cell power systems. He was elected as a Fellow of the U.K. Institution of Mechanical Engineers in 2000 and a Fellow of the Society of Automotive Engineers in 2014. He is currently the Chair of the U.K. Section of SAE International.

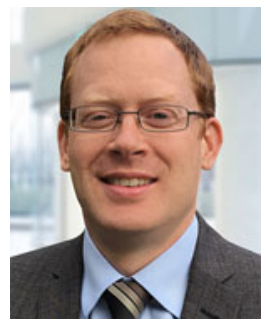

Byron Mason received the B.E. degree in mechanical engineering and Ph.D. degree in powertrain calibration and control the University of Bradford, Bradford, U.K., in 2005 and 2009, respectively.

$\mathrm{He}$ is currently a Senior Lecturer in intelligent powertrain systems with the Department of Aeronautical and Automotive Engineering, Loughborough University, Loughborough, U.K. $\mathrm{He}$ is also academic lead for the APC Digital Engineering and Test Spoke as well as sitting on the management board of the Digital Engineering and Test Centre hosted at Loughborough University, London, U.K.

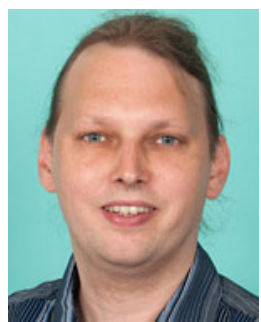

Thomas Steffen (M'12) received the B.E. degree in electrical engineering from the Technical University IImenau, IImenau, Germany, in 1999, and the Ph.D. degree in electrical engineering from the Ruhr-Universitat Bochum, Bochum, Germany, in 2004.

Since 2010, he has been a Lecturer and then a Senior Lecturer of control engineering with the Department of Aeronautical and Automotive Engineering, Loughborough University, Loughborough, U.K. His research interests include design and control of energy systems, including electric motors, internal combustion engines, and after-treatment systems.

Dr. Steffen is a member of the SAE. 